\title{
Priming of short-term potentiation and synaptic tagging/capture mechanisms by ryanodine receptor activation in rat hippocampal CAl
}

\author{
Sreedharan Sajikumar, ${ }^{1,4,5}$ Qin Li, ${ }^{1,2}$ Wickliffe C. Abraham, ${ }^{3}$ and Zhi Cheng Xiao ${ }^{1,2,5}$ \\ ${ }^{1}$ Department of Clinical Research, Singapore General Hospital, Singapore 169608; ${ }^{2}$ Institute of Molecular and Cell Medicine, \\ Kunming Medical College, Kunming 650032, People's Republic of China; ${ }^{3}$ Department of Psychology and the Brain Health and \\ Repair Research Centre, University of Otago, Dunedin 9054, New Zealand
}

\begin{abstract}
Activity-dependent changes in synaptic strength such as long-term potentiation (LTP) and long-term depression (LTD) are considered to be cellular mechanisms underlying learning and memory. Strengthening of a synapse for a few seconds or minutes is termed short-term potentiation (STP) and is normally unable to take part in the processes of synaptic tagging / capture due to its inability to set the "synaptic tags." Here, we report that priming of synapses with ryanodine receptor agonists such as ryanodine $(10 \mu \mathrm{M})$ or caffeine $(10 \mathrm{mM})$ facilitates subsequent synaptic tagging/capture, enabling an STP protocol to establish a late-LTP in response to strong tetanization of a heterosynaptic input. We identified calcium / calmodulin-dependent protein kinase II (CaMKII) as mediating the primed synaptic tag setting, which persisted for $1 \mathrm{~h}$. We also identified protein kinase $\mathrm{M} \zeta(\mathrm{PKM} \zeta)$, presumably captured from the strongly tetanized heterosynaptic input, as a plasticity-related protein maintaining the LTP at the tagged synapses. In addition, synaptic tags in primed STP were erased or interfered with by delivering low-frequency depotentiating stimulation 5 or 10 min after its induction, thus preventing capture of newly synthesized proteins. These data reveal a novel form of metaplasticity, whereby ryanodine receptor activation lowers the threshold for subsequent synaptic tagging/capture, thus priming weakly activated synapses for heterosynaptic interactions that promote long-term functional plasticity.
\end{abstract}

Long-term potentiation (LTP) and long-term depression (LTD) can be regulated by the previous history of synaptic activation. This form of plasticity regulation is termed "metaplasticity" (Abraham 2008). One of the important functions of metaplasticity is to provide a mechanism for integrating synaptic events across periods of time that are orders of magnitude longer than the tens of milliseconds typical of temporal summation of synaptic potentials (Abraham 1999). One example of how prior synaptic activity can integrate synaptic signals over a particular time interval is revealed by the synaptic tagging model (Frey and Morris 1997). In this model, newly synthesized "plasticity-related proteins" (PRPs) from a late-LTP can transform a transient early-LTP to a late-LTP in a nearby input (Frey and Morris 1997). According to this model, early-LTP sets "synaptic tags" that marks these synapses so that they can capture PRPs from the late-LTP inputs as long as the tags survive (Sossin 1996; Frey and Morris 1998b). However, short-term potentiation (STP), which lasts for only 10-15 min, does not set a "tag, and these synapses are thus not able to capture PRPs (Frey and Morris 1997). It has been reported that activity prior to, or immediately after the induction of early-LTP can inhibit PRP capture, presumably by erasing or otherwise interfering with the synaptic tags and thus preventing any form of functional plasticity (Sajikumar and Frey 2004b; Young and Nguyen 2005). In contrast to the previous studies on synaptic tagging (Sajikumar and Frey 2004a; Sajikumar et al. 2005b, 2007a,b), here we will refer to the synaptic tagging processes as synaptic tagging/ capture, as suggested by others (Kelleher III et al. 2004; Young and Nguyen 2005; Barco et al. 2008), since synaptic tagging involves two serial processes: (1) setting of the synaptic tag as triggered by a specific

\footnotetext{
${ }^{4}$ Present address: Zoological Institute Division of Cellular Neurobiology, 38106 Braunschweig, Germany.

${ }^{5}$ Corresponding authors.

E-mail S.sajikumar@tu-bs.de; fax 49-531391-3222.

E-mail Zhicheng.xiao@hotmail.com; fax 65-6321-3606.

Article is online at http://www.learnmem.org/cgi/doi/10.1101//m.1255909.
}

pattern of stimulation, and (2) synaptic capture, whereby the synaptic tag interacts with newly synthesized PRPs.

In the hippocampus, the ability of priming activation of Group 1 metabotropic glutamate receptors (mGluRs) to facilitate the induction and persistence of LTP has been well studied (Bortolotto et al. 1994; Cohen and Abraham 1996). mGluR priming of LTP is mediated by activation of phospholipase C (Cohen et al. 1998), release of $\mathrm{Ca}^{2+}$ from intracellular stores via ryanodine receptor (RYR) activation, and entry of $\mathrm{Ca}^{2+}$ through store-operated $\mathrm{Ca}^{2+}$ channels in the plasma membrane (Mellentin et al. 2007). Furthermore, direct activation of the ryanodine receptors is sufficient to prime subsequent LTP (Mellentin et al. 2007). The priminginduced facilitation of LTP persistence is due to stimulation of local synaptic protein synthesis (Raymond et al. 2000), with the newly synthesized proteins apparently being kept in reserve for enhancing the persistence of subsequent plasticity.

In the present study we provide evidence that priming of RYRs not only facilitates LTP induction homosynaptically, but also lowers the threshold for synaptic tagging/capture such that STP protocols set synaptic tags, enabling heterosynaptic interactions that convert the primed STP to late-LTP. Primed tag setting entails CaMKII activation for up to $1 \mathrm{~h}$, enabling the synapses to capture PRPs over this time period. A key PRP captured at the primed synapses is PKM $\zeta$, since a PKM $\zeta$ inhibitor completely reversed the late-LTP generated by these processes. In addition, application of low-frequency stimulation 5 or $10 \mathrm{~min}$, but not $15 \mathrm{~min}$, after the establishment of primed STP effectively prevented the capture processes.

\section{Results}

STP and synaptic tagging/ capture

In the first set of experiments, we induced late-LTP with a duration of at least $6 \mathrm{~h}$ by using STET in synaptic input S1 (Fig. 1B, filled 
A
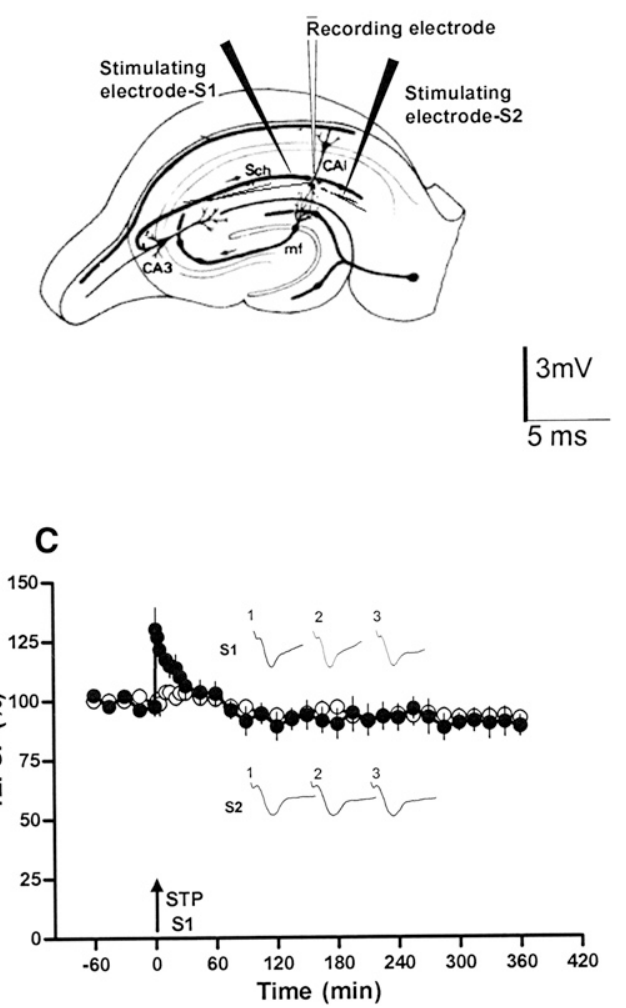

B

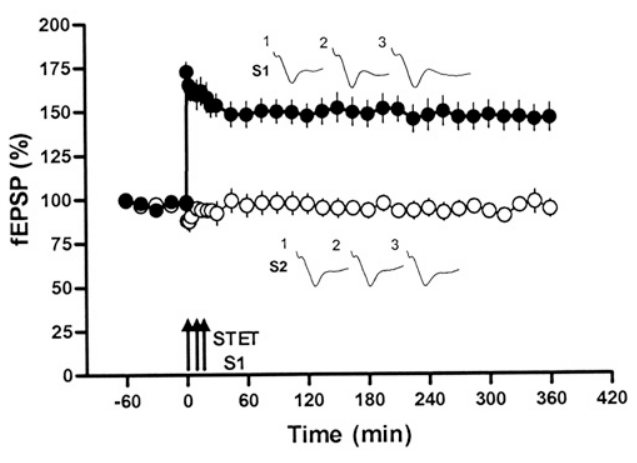

D

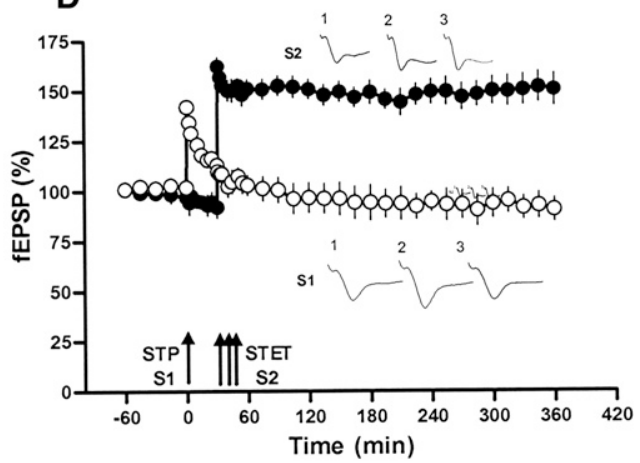

Figure 1. STP fails to trigger synaptic tagging/capture. ( $A$ ) Schematic of a hippocampal slice showing positions of two stimulating electrodes (S1 and S2) and a single recording electrode placed in the stratum radiatum of area CA1. (B) The time course of late-LTP induced in S1 (•) by a strong tetanization protocol (STET); (O) baseline control stimulation of S2 $(n=6)$. (C) STP induced by very weak tetanization in S1 (•), which lasts only $10-15$ min $(n=6)$. (D) STP was induced in S1 (O) 30 min prior to late-LTP induction in S2 (•). STP in S1 decayed to the baseline after 15 min and late-LTP remained stable in S2, showing no tagging/ capture interaction $(n=6)$. Single arrow represents very weak tetanization applied for inducing STP. Triplet of arrows represents strong tetanization for inducing late-LTP. Insets show traces recorded from synaptic input S1 and S2, $30 \mathrm{~min}$ before (1), $30 \mathrm{~min}$ after (2), and $6 \mathrm{~h}$ after (3), respectively. Error bars indicate SEM.

circles). Low-frequency control stimulation of an independent input $\mathrm{S} 2$ to the same neuronal population had no significant effect on baseline potentials (Fig. 1B, open circles). Potentials in S1 were statistically significantly potentiated for the entire recording period of $360 \mathrm{~min}$ (Mann-Whitney $U$-test; $P<0.05$ and Wilcoxon signed rank test; $P<0.05)$. Properties of this late-LTP were similar to those described earlier (Sajikumar et al. 2005a). In a second set of control experiments, a single very weak tetanus was delivered to input S1, which resulted in STP (Fig. 1C, filled circles) that decayed to baseline within 10-15 min. The time course of the baseline potentials in control input $\mathrm{S} 2$ was stable throughout the recording period (Fig. 1C, open circles). In the third set of experiments, by using a weak-before-strong paradigm (Frey and Morris 1998b), STP was induced in synaptic input S1, and 30 min later, STET was applied to synaptic input S2 for inducing late-LTP in this pathway. This procedure failed to transform STP in S1 to late-LTP (Fig. 1D, open circles). Potentials in S1 were statistically significantly potentiated only up to $5 \mathrm{~min}$ (Mann-Whitney $U$-test; $P<0.05$ and Wilcoxon signed rank test; $P<0.05$ ). The post-tetanization potentials of S2 (filled circles) were statistically significantly potentiated up to the end of the recording period when compared with its own baseline (Wilcoxon signed rank test; $P<0.05$ ).

\section{Primed STP and synaptic tagging / capture}

Mellentin et al. (2007) reported that a low dose of RYA (10 $\mu \mathrm{M})$, as well as a high dose of the RYR agonist caffeine $(10 \mathrm{mM})$, can prime
LTP. We have replicated these data in our experimental conditions (data not shown). We next asked whether RYA or caffeine can prime STP. To address this question, a stable baseline of $30 \mathrm{~min}$ was recorded, after which RYA $(10 \mu \mathrm{M})$ was bath applied for $30 \mathrm{~min}$ and then washed out for a further $30 \mathrm{~min}$ (Fig. 2A). STP was induced in synaptic input S1 30 min after washout of the drug (thus, a total of 90 min baseline). Primed STP showed increased potentiation (Fig. 2A, filled circles) during induction compared with control STP (Fig. 1C), and the potentials were statistically significantly potentiated for up to $30 \mathrm{~min}$ (Mann-Whitney $U$-test; Wilcoxon signed rank test; $P<0.05)$. The same experimental design was used for caffeine $(10 \mathrm{mM})$ priming. Similar to RYAprimed STP, caffeine-primed STP also showed enhanced potentiation during induction, and the potentials were statistically significantly potentiated for up to $45 \mathrm{~min}$ (Fig. 2B, filled circles). In both cases, the control synaptic input $\mathrm{S} 2$ remained stable for the entire recording period (Fig. 2A,B, open circles).

In a critical next series of experiments, we addressed the question of whether RYA- or caffeine-primed STP can take part in synaptic tagging/capture (Fig. 2C-H). We used the weak-beforestrong protocol, in which RYA $(10 \mu \mathrm{M})$ or caffeine $(10 \mathrm{mM})$ was bath applied for $30 \mathrm{~min}$ during baseline and washed out $30 \mathrm{~min}$ before the induction of STP in S1. Primed STP in S1 (Fig. 2C-H, open circles) was followed by STET in S2 to induce late-LTP at these synapses (Fig. 2C-H, filled circles). Unlike control STP, primed STP could be transformed to late-LTP if the strong tetanus was applied 

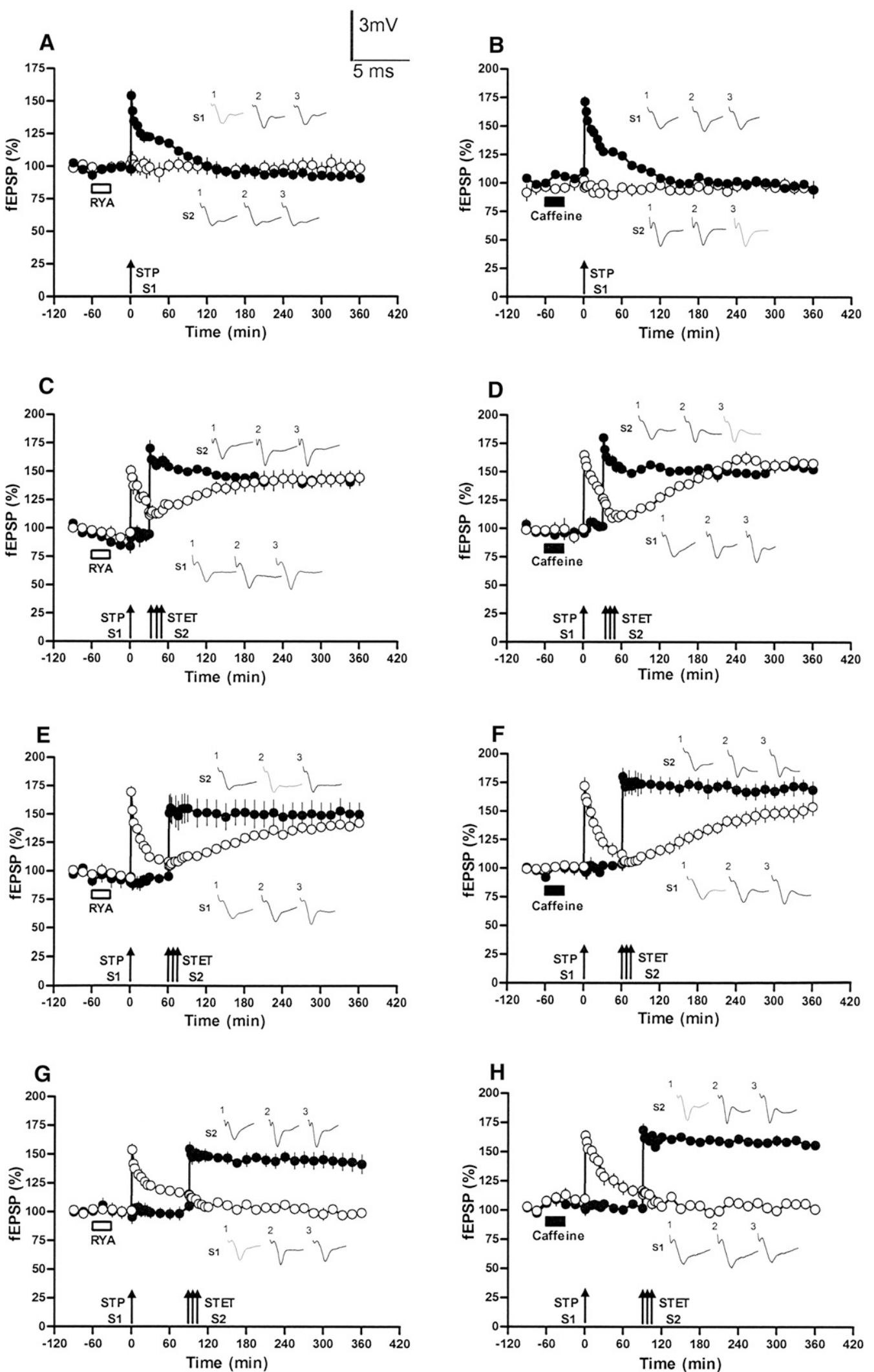

Figure 2. Priming of STP and synaptic tagging/capture. $(A, B)$ Administration of RYA $(10 \mu M)$ or caffeine $(10 \mathrm{mM})$ for 30 min, and then washout for 30 min prior to STP induction did not affect baseline responses (O), but STP was facilitated for 30-40 min $(\bullet, A, n=6 ; B, n=5)$. (C-H) RYA or caffeine priming followed by STP in S1 (O) and subsequent induction of late-LTP in S2 (•). Primed STP was transformed into late-LTP, in that input when the interval between STP and the STET was $(C, D) 30 \mathrm{~min}(C, n=6 ; D, n=4)$, or $(E, F) 60 \min (E, n=6 ; F, n=4),(G, H)$ but was absent when the interval increased to 90 $\min (G, n=6 ; H, n=4)$. Error bars indicate SEM. Symbols and traces as in Figure 1 . 
either $30 \mathrm{~min}$ (Fig. 2C,D) or $1 \mathrm{~h}$ (Fig. 2E,F), but not $90 \mathrm{~min}$ (Fig. $2 \mathrm{G}, \mathrm{H})$ later. Thus, the primed STP was able to generate synaptic tags that lasted between 30 and $60 \mathrm{~min}$. In all cases (Fig. 2C-F), potentials in S1 (open circles) were statistically significantly potentiated initially for up to 25-30 min (Wilcoxon signed rank test; $P<0.05$ ), and then again from $60 \mathrm{~min}$ (Fig. $2 \mathrm{C}$, open circles), $120 \mathrm{~min}$ (Fig. 2D,E, open circles), or $135 \mathrm{~min}$ onward (Fig. 2F, open circles, Wilcoxon signed rank test; $P<0.05)$. Post-tetanization potentials in S2 (filled circles) showed significant potentiation compared with their prepotentiation values at all time points in all experiments (Fig. 2C-H, Wilcoxon signed rank test; $P<0.05$ ).

\section{Identity of synaptic tags and PRPs in primed STP}

In synaptic tagging/capture, the specificity of plasticity is achieved by the activation of process- and compartment-specific synaptic tag molecules (Alarcon et al. 2006; Sajikumar et al. 2007a). It has been recently shown that CaMKII mediates setting of synaptic tags in apical dendrites, while PKA or PKM $\zeta$ is required for setting synaptic tags in basal dendrites in hippocampal CA1 (Sajikumar et al. 2007a). We asked whether CaMKII mediates synaptic tagging in apical dendrites in primed STP, similar to conventional tagging. To address this question, we bath applied the specific CaMKII inhibitors KN-62 and AIP at a concentration $(5 \mu \mathrm{M})$ that blocks CaMKII-mediated synaptic tags in conventional tagging experiments (Sajikumar et al. 2007a). In each experiment, a stable baseline of $30 \mathrm{~min}$ was recorded before a 30-min bath application of RYA or caffeine (Fig. 3A-D). Immediately after the washout of RYA or caffeine, KN-62 or AIP was bath applied for the next $1 \mathrm{~h}$. STP was induced in S1 (open circles) 30 min before the washout of the CaMKII inhibitors. In synaptic input S2, late-LTP was induced $1 \mathrm{~h}$ after the induction of STP. As predicted, primed STP in synaptic input $\mathrm{S} 1$ failed to transform to late-LTP, thus revealing a critical role for CaMKII in setting or maintaining the synaptic tags in primed STP. In all cases, potentials in S1 (Fig. 3A-D, open circles) were statistically significantly potentiated for only up to $15-30$ min (Wilcoxon signed rank test; $P<0.05$ ). Post-tetanization potentials in S2 (filled circles) in all cases showed significant potentiation compared with their own prepotentiation values (Wilcoxon signed rank test; $P<0.05$ ).

Our experiments demonstrate that the molecular process of synaptic tagging in primed STP resembles that of conventional LTP tagging, at least in the requirement for CaMKII activity in CA1 pyramidal cell apical dendrites (Sajikumar et al. 2007a). The next question was what PRPs are captured by the synaptic tags in primed STP? It has been shown earlier that PKM $\zeta$ is an LTP-specific PRP and capturing PKM $\zeta$ generated from a strongly tetanized input is critical for conventional LTP-tagging interactions (Sajikumar et al. 2005a). To test whether a similar mechanism was active in the present paradigm, myr-ZIP $(1 \mu \mathrm{M})$, a specific inhibitor of $\mathrm{PKM} \zeta$, was applied $30 \mathrm{~min}$ after the induction of late-LTP in S2 and continued for $360 \mathrm{~min}$ (Fig. 3E,F, filled circles). We observed that myr-ZIP prevented the potentiation of the primed input by the heterosynaptic STET (Fig. 3E,F). In experiments using the control peptide scr-myr-ZIP $(1 \mu \mathrm{M})$, the tag and capture interactions remained intact (Fig. 3G). In Figure 3E,F, potentials in S1 (open circles) were statistically significantly potentiated only up to 25 min, and in Figure $3 \mathrm{G}$, statistically significant potentiation was again observed from 120 min onward (Wilcoxon signed rank test; $P<0.05$ ). Post-tetanization potentials in S2 (filled circles) showed significant potentiation for up to $120 \mathrm{~min}$ in Figure 3E,F and during the entire recording period in Figure 3G (Wilcoxon signed rank test; $P<0.05$ ). Thus, our experiments support $\mathrm{PKM} \zeta$ being required for generating the late-LTP induced by primed STP tagging and capture.

In the next series of experiments, we checked whether PKM $\zeta$ continues to mediate late-LTP long after its establishment in the primed pathway. The experimental design was similar to that in Figure 3E,F, except that myr-ZIP $(1 \mu \mathrm{M})$ was applied $4 \mathrm{~h}$ after the induction of RYA or caffeine-primed STP and through to the end of the experiment $(8 \mathrm{~h})$. PKM $\zeta$ inhibition prevented late-LTP maintenance in both synaptic input S1 and S2. Potentials in S1 were statistically significantly potentiated up to $35 \mathrm{~min}$ initially, and again, statistically significant potentiation was observed from 75 min up to 330 min in Figure 3H,I (open circles) (Wilcoxon signed rank test; $P<0.05$ ). Post-tetanization potentials in $\mathrm{S} 2$ (filled circles) showed significant potentiation for up to $345 \mathrm{~min}$ in Figure $3 \mathrm{H}$ and up to $330 \mathrm{~min}$ in Figure 3I (Wilcoxon signed rank test; $P<$ $0.05)$.

\section{Depotentiation and primed STP}

In the next series of experiments we investigated the effect of lowfrequency stimulation (LFS, 250 pulses at $1 \mathrm{~Hz}$ ) on primed STP. It had been reported earlier that application of LFS immediately after the induction of early-LTP can depotentiate early-LTP and interfere with or erase the synaptic tags (Sajikumar and Frey 2004b). As seen in Figure 4A,B (filled circles), LFS, given 5 min after RYA- or caffeine-primed STP, completely reversed the primed STP. Potentials in S1 were statistically significantly potentiated only up to 5 min (Mann-Whitney $U$-test; $P<0.05$ and Wilcoxon signed rank test; $P<0.05)$. In both cases, the control synaptic input S2 remained stable for the entire recording period (Fig. 4A,B, open circles). In the next set of experiments we increased the time interval between the induction of primed STP and application of LFS from 5 to $10 \mathrm{~min}$ in S1 (Fig. 4C,D), which again resulted in a complete reversal of primed STP. Application of LFS with a 15min delay resulted in a transient depotentiation and an incomplete recovery of primed STP for $\sim 10 \mathrm{~min}$ before resuming its normal transient maintenance, decaying to baseline after $30 \mathrm{~min}$ (Fig. 4E,F, filled circles). Potentials in S1 after LFS were statistically significantly potentiated only from 20 to $30 \mathrm{~min}$ (Mann-Whitney $U$-test; $P<0.05$ and Wilcoxon signed rank test; $P<0.05)$. The control synaptic input $\mathrm{S} 2$ remained stable for the entire recording period (Fig. 4E,F, open circles). Thus, our experiments reveal that the effective time window for erasing primed STP is within $10 \mathrm{~min}$.

\section{Depotentiated primed STP and synaptic tagging / capture} Sajikumar and Frey (2004b) reported that LFS 5 min after the induction of early-LTP erases synaptic tags, and this depotentiated early-LTP was unable to capture PRPs. We tested whether depotentiated primed STP has similar properties. First, we reproduced the experimental paradigm described in Figure 4, with the addition $30 \mathrm{~min}$ after the induction of primed STP in S1, lateLTP was induced in the second synaptic input S2 (Fig. 5, filled circles). Induction of late-LTP $30 \mathrm{~min}$ after the STP had no effect on primed STP that had been depotentiated 5 or 10 min after induction. Thus, depotentiation of primed STP erased or interfered with the synaptic tags in these inputs, resulting in no capture of PRPs from late-LTP in S2 (Fig. 5A-D, open circles). Experiments shown in Figure 5E,F revealed that application of LFS 15 min after the induction of RYA- or caffeine-primed STP did not affect the synaptic tags, since the synaptic input $\mathrm{S} 1$ was capable of capturing PRPs from the late-LTP in S2. Potentials in S1 (open circles) were statistically significantly potentiated initially for up to 5 min in Figure 5A,B and $10 \mathrm{~min}$ in Figure 5C,D. In Figure 5E,F potentials were significantly potentiated up to $15 \mathrm{~min}$ posttetanization (Wilcoxon signed rank test; $P<0.05$ ) and again from $75 \mathrm{~min}$ on. Post-tetanization potentials in S2 (filled circles) showed significant potentiation compared with their prepotentiation values in all experiments (Fig. 5A-F, Wilcoxon signed rank test; $P<0.05)$. 

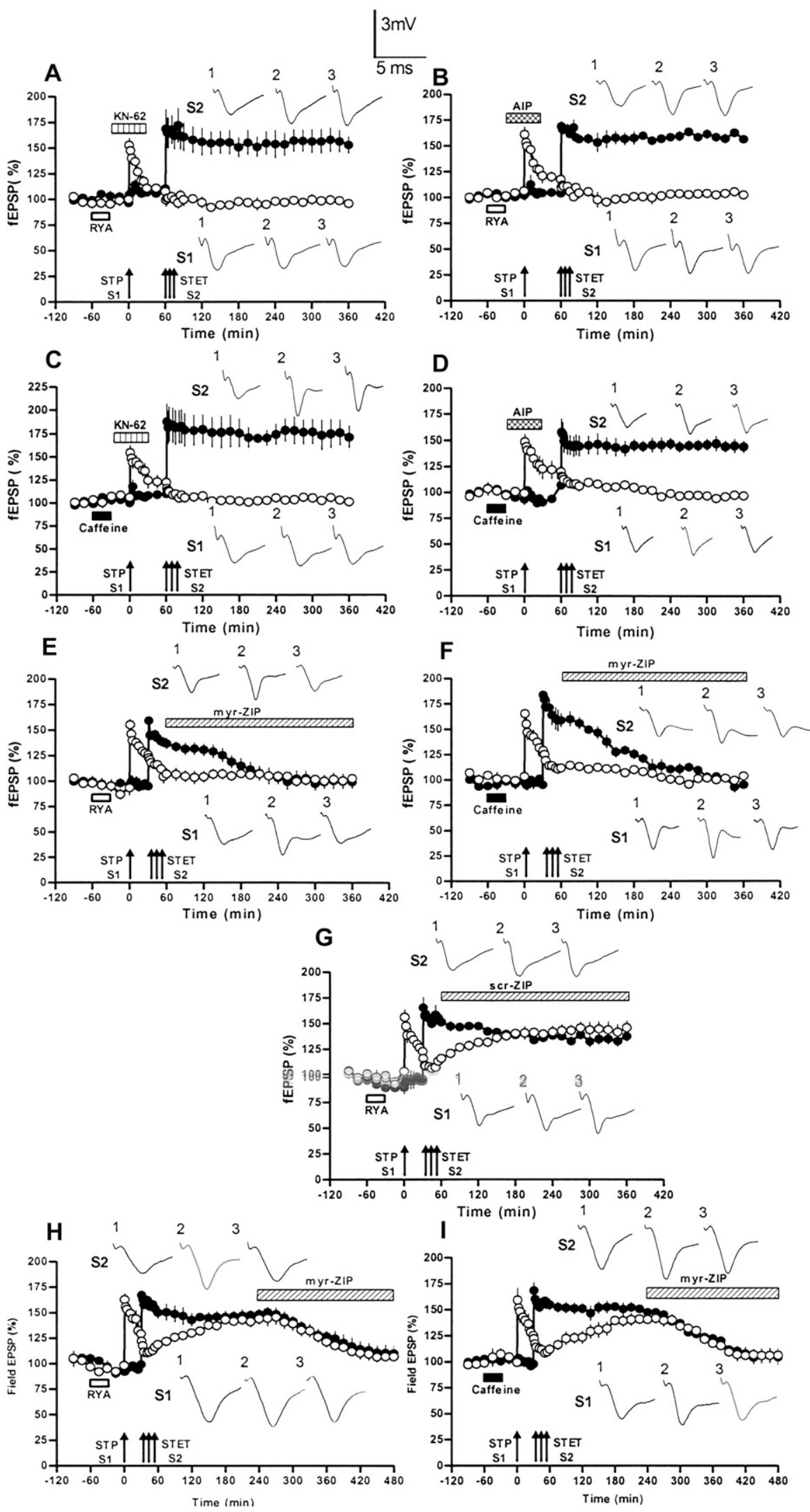

Figure 3. (Legend on next page)

\section{Discussion}

There are considerable data showing that prior neural activity can tune synapses and networks for plasticity. For example, pharmacological or synaptic activation of NMDA receptors can inhibit the induction of subsequent LTP (Coan et al. 1989; Youssef et al. 2006), while activation of group 1 mGluRs facilitates both induction and persistence of subsequent LTP in area CA1 (Cohen and Abraham 1996; Manahan-Vaughan and Reymann 1997; Cohen et al. 1998; Bortolotto and Collingridge 1999; Ireland and Abraham 2002). The mGluR priming effect is mediated by release of calcium from intracellular stores via ryanodine receptors, and direct activation of the ryanodine receptors is sufficient to prime LTP (Mellentin et al. 2007). Ryanodine receptors are important for LTP and deletion of ryanodine receptor type 3 impairs synaptic plasticity and spatial learning (Balschun et al. 1999). RYRs are modulated by ryanodine, which binds to high- or low-affinity sites in a concentration-dependent dual manner. A low concentration of ryanodine $(\leq 10$ $\mu \mathrm{M})$ locks the channel in a subconductance "open state," whereas higher concentrations $(100 \mu \mathrm{M})$ result in channel blockade (Meissner 1986; Rousseau et al. 1987; McPherson et al. 1991).

Earlier studies have shown that STP is unable to set a synaptic tag or synthesize PRPs (Frey and Morris 1997). Due to the inability to set a synaptic tag, STP is incapable of capturing PRPs from a neighboring input that has been strongly tetanized (Frey and Morris 1997, 1998a). Our results show that delivery of RYR agonists like ryanodine or caffeine $30 \mathrm{~min}$ before the induction of STP can prime the synapses, leading to a larger and more persistent form of potentiation that is nonetheless still decremental. We hypothesize here that the primed STP is a form of early-LTP, having similar properties to that of conventional early-LTP induced by a stronger tetanization protocol, apart from its somewhat shorter duration and more prolonged sensitivity to subsequent LFS (see below). Consistent with the earlier findings, we also observed that the priming signal needs to occur sufficiently ahead of the STP protocol (Mellentin et al. 2007), as priming that ended $10 \mathrm{~min}$ before the weak tetanization had no effect on STP and synaptic tagging (data not shown). Furthermore, the effects of the priming stimulation were restricted to the STP synapses of S1, with no evidence of an influence of priming on late-LTP in S2. We induced late-LTP between 60 and $120 \mathrm{~min}$ after washout of the drugs, and did not observe any effects on late-LTP in S2. 
Importantly, we observed a novel metaplasticity feature of RYR activation, namely, lowering the threshold for setting a synaptic tag. Thus, RYR-primed synapses receiving the STP protocol became able to generate a synaptic tag and capture PRPs generated after strong tetanization of a nearby synaptic input. The newly created tags in primed STP could last for up to $1 \mathrm{~h}$. Ryanodinemediated signals are generally confined to dendritic spines, and this raises the possibility that RYR-dependent LTP might be confined to a subpopulation of synapses that mainly utilizes local protein synthesis for its persistence (Raymond 2007). It has been reported recently that functional processes like synaptic tagging/ capture and cross-tagging are compartment restricted and utilize CaMKII to mediate setting of the synaptic tags, which then capture proteins generated by local protein synthesis (Alarcon et al. 2006; Sajikumar et al. 2007a). Similarly, we have shown that the specific CaMKII inhibitors, $\mathrm{KN}-62$ and AIP, prevented the transformation of STP to late-LTP. Thus, the molecular process of setting synaptic tags, primed by RYR activation, resembles that of conventional LTP tagging processes (Sajikumar et al. 2007a). This result is consistent with recent findings that CaMKII plays a role in actin bundling during the basal state in dendritic spines (Okamoto et al. 2007), thereby affecting the structural plasticity of spines. Structural changes may contribute to the effective setting of tags in the activated synapses (Martin and Kosik 2002). Although these data appear best interpreted as CaMKII playing an important role in setting the synaptic tags in primed STP, it could be hypothesized that application of the CaMKII inhibitor immediately after RYR priming might have impaired the function or persistence of tags that had been already set during RYR stimulation. However, we have ruled out this latter possibility by the observation that RYR activation alone is insufficient to permit an input to capture PRPs (S. Sajikumar and W.C. Abraham, unpubl.).

In addition to CaMKII, protein kinase A (PKA) may also play a role in setting the synaptic tags in caffeine-primed STP. In addition to activating RYRs, caffeine is a phosphodiesterase inhibitor and may exert its effect by inhibiting cAMP degradation, leading to more PKA activation (van Staveren et al. 2001; Yoshimura 2005). The role of cAMP and PKA in more established forms of synaptic tagging/capture has been well documented (Navakkode et al. 2004 ; Young et al. 2006).

We also asked whether PKM $\zeta$ served as a PRP that was captured by the CaMKII-mediated tags in primed STP, since PKM $\zeta$ mediates synaptic potentiation specifically during the late phase of LTP (Sajikumar et al. 2005b; Ling et al. 2006). Late-phase LTP induction increases new PKM $\zeta$ synthesis (Hernandez et al. 2003; Ling et al. 2006), and the increased level of PKM $\zeta$ then enhances synaptic transmission by doubling the number of postsynaptic AMPA receptors (AMPAR) through GluR2 subunit-mediated trafficking of the receptors to the synapse (Sacktor 2008; Yao et al. 2008). Application of the specific inhibitor myr-ZIP prevented the triggering of late-LTP in the primed STP input by strong tetanization of neighboring synapses, supporting early findings using the conventional synaptic tagging/capture paradigm (Sajikumar et al. 2005a). In the presence of a control peptide of ZIP, tagging interactions were intact. It has been reported earlier that persistent, increased phosphorylation by PKM $\zeta$ specifically maintains the late phase of LTP, since application of the PKM $\zeta$ inhibitors 3 or $5 \mathrm{~h}$ after the induction of late-LTP prevents its maintenance (Serrano et al. 2005). Our results also support this finding, as PKM $\zeta$ inhibition $4 \mathrm{~h}$ after primed STP tagging/capture prevented the maintenance of this late-LTP. Thus, in general, our data are consistent with the recent findings that PKM $\zeta$ not only maintains LTP, but also is a newly synthesized protein that promotes late-LTP development by releasing AMPARs from an extra-synaptic pool and enhancing NSF/GluR2-mediated trafficking of them to the synapses (Yao et al. 2008).

LTP can be depotentiated if LFS is applied to the potentiated input shortly after its induction (Martin 1998). Homosynaptic LFS within a short interval after the induction of early-LTP also effectively impairs or erases synaptic tags. While the effective time frame for affecting the synaptic tags in early-LTP is 5 min after its induction (Sajikumar and Frey 2004b), tags set by primed STP were affected by LFS up to 10 min after induction. Thus, the tags set by primed STP stimulation are more fragile than the tags set by stimulation that evokes early-LTP.

Computational models predict that the temporal and spatial characteristics of input activity to a neuron determines which information is stored in the neuronal networks over a period of time for memory engrams (Mel 1993; Govindarajan et al. 2006). Behaviorally relevant stimuli should activate storage processes proportional to both the strength of the synaptic tag and the local concentration of essential protein. In contrast, behaviorally irrelevant information (here STP) would not be stored (Govindarajan et al. 2006), presumably by being subthreshold for synaptic tagging and capture. Here, we provide the first evidence that weakly activated synapses can become enabled for long-term heterosynaptic plasticity interactions through a metaplastic priming event. Thus, the threshold for synaptic tagging and capture is modifiable and responsive to the prior history of neural activation.

\section{Materials and Methods}

Hippocampal slices were prepared from male Wistar rats (6-7-wk old). All procedures were approved by the Singhealth Committee on Ethics in the Care and Use of Laboratory animals. Rats were anesthetized with pentabarbitone $(50 \mathrm{mg} / \mathrm{kg}$ i.p.) and decapitated. The brain was quickly removed and cooled in $2^{\circ} \mathrm{C}-4^{\circ} \mathrm{C}$ artificial cerebrospinal fluid (ACSF). Transverse hippocampal slices $(400 \mu \mathrm{m})$ were prepared from the right hippocampus by using a manual tissue chopper, and the slices were incubated at $32^{\circ} \mathrm{C}$ in an interface chamber (Scientific System Design), which was slightly modified for long-term functional studies up to $6-8 \mathrm{~h}$. The ACSF contained the following (in millimolars): $124 \mathrm{NaCl}, 4.9 \mathrm{KCl}, 1.2 \mathrm{KH}_{2} \mathrm{PO}_{4}, 2.0$ $\mathrm{MgSO}_{4}, 2.0 \mathrm{CaCl}_{2}, 24.6 \mathrm{NaHCO}_{3}, 10$ D-glucose, equilibrated with $95 \% \mathrm{O}_{2}-5 \% \mathrm{CO}_{2}(20 \mathrm{~L} / \mathrm{h})$, and the flow rate of ACSF was $0.87 \mathrm{~mL} /$ min. In all experiments, two monopolar lacquer-coated, stainless-steel electrodes (5 $\mathrm{M} \Omega$; AM Systems USA) were positioned at an adequate distance within the stratum radiatum of the CA1 region for stimulating two separate independent synaptic inputs S1 and S2 of one neuronal population (Fig. 1A; Frey and Morris 1997; Sajikumar et al. 2005a). For recording the field EPSP (measured as its slope function), one electrode (5 M $\Omega$; AM Systems) was placed in the CA1 apical dendritic layer, and signals were amplified by a differential amplifier (Model 1700, AM Systems). The signals were digitized using a CED 1401 analog- 
A

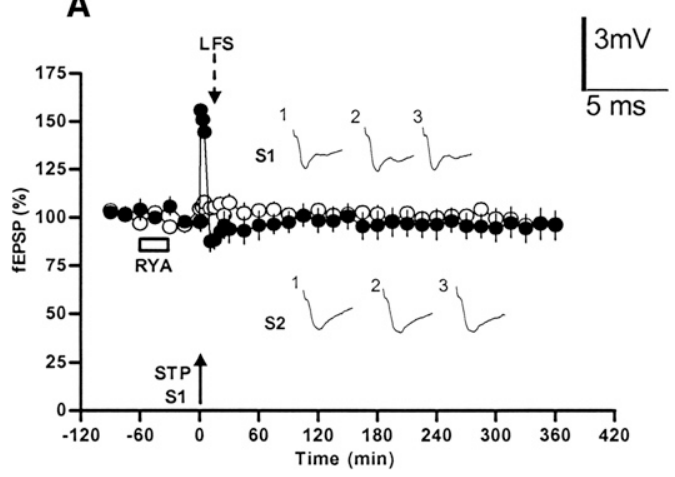

C
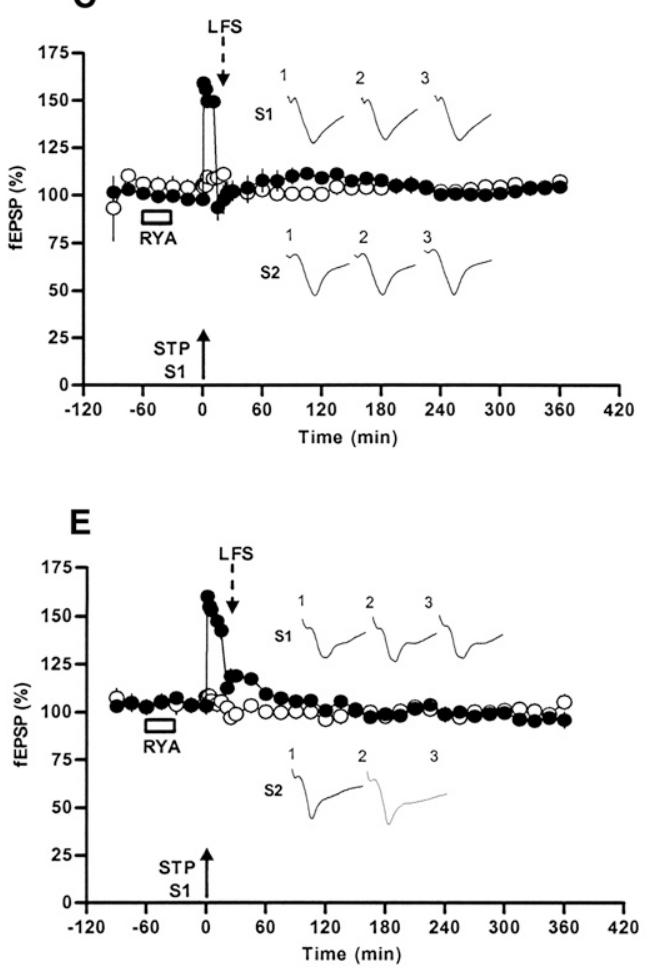

B

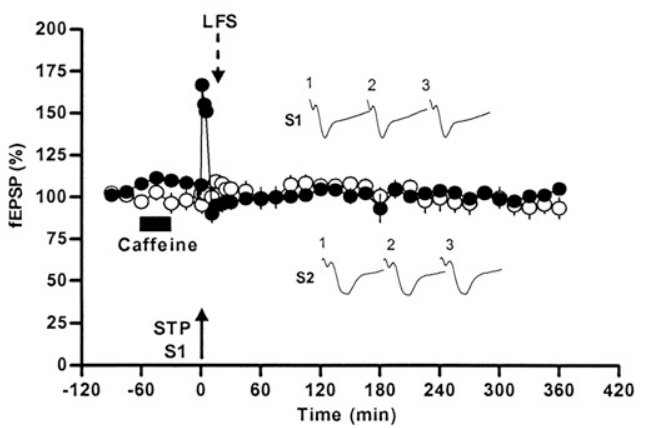

D

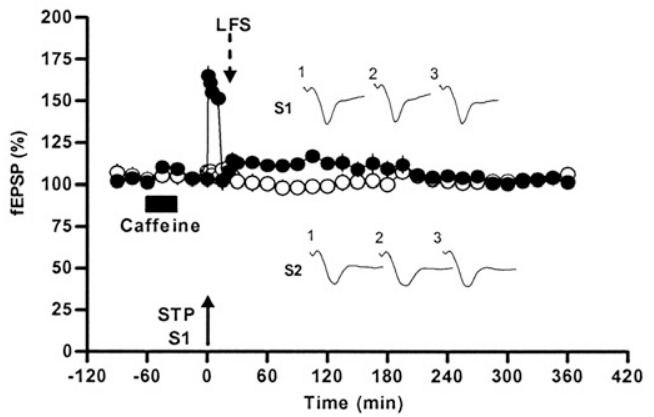

$\mathbf{F}$

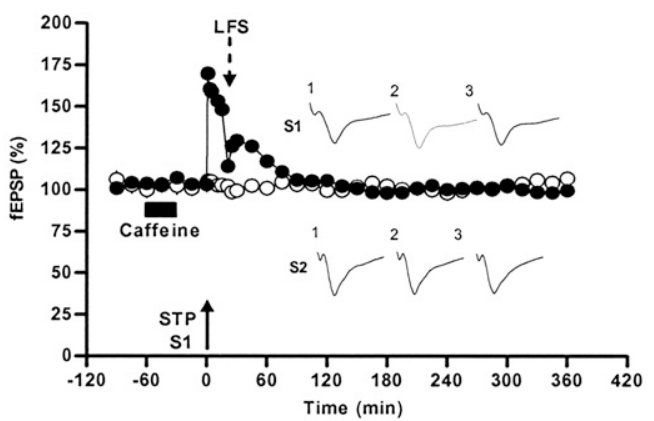

Figure 4. Depotentiation of primed STP. $(A, B)$ LFS 5 min after primed-STP of S1 resulted in a complete depotentiation of RYA- $(n=6)$ or caffeine-primed STP $(n=5)(\bullet)$. (C,D) Similar to $A$ and $B$, but DP was applied 10 min after RYA- $(n=6)$ or caffeine-primed-STP $(n=5)$. $(E, F)$ DP 15 min after RYA- $(n=6)$ or caffeine-primed STP $(n=5)$ resulted in reversal of STP and then an incomplete recovery of potentials lasting 15 min before reaching baseline levels. Open circles represent baseline control stimulation of S2. Broken arrow represents the time point where LFS was applied for depotentiation in the corresponding synaptic input. Error bars indicate SEM. Symbols and traces as in Figure 1.

to-digital converter (Cambridge Electronic Design) and analyzed with Signal 4 software (CED). Slices were preincubated for $3 \mathrm{~h}$, which is critical for late-plasticity studies (Sajikumar et al. 2005a). After the preincubation period, an input-output curve (afferent stimulation vs. fEPSP slope) was plotted prior to experiments. For setting the test stimulus intensity, a fEPSP of $40 \%$ of its maximal amplitude was determined for both synaptic inputs, S1 and S2. For stimulation, biphasic constant-current pulses were used. Late-LTP was induced using three stimulus trains of 100 pulses ("strong" tetanus [STET], $100 \mathrm{~Hz}$; duration, $0.2 \mathrm{msec} /$ polarity; intertrain interval, $10 \mathrm{~min}$ ). Short-term potentiation (STP) was induced using a very weak tetanization protocol consisting of one $100-\mathrm{Hz}$ train (14 biphasic constant-current pulses; pulse duration per half wave, $0.2 \mathrm{msec}$ (Sajikumar et al. 2007a). Low-frequency stimulation (LFS) was applied 5, 10, or $15 \mathrm{~min}$ after the induction of primed STP in the same synaptic input using 250 impulses at a frequency of $1 \mathrm{~Hz}$
(Sajikumar and Frey 2004b). The slopes of the fEPSPs were monitored on-line. The baseline was recorded for 60 or 90 min for control or priming experiments. Four $0.2-\mathrm{Hz}$ biphasic constant-current pulses $(0.1 \mathrm{msec} /$ polarity) were used for baseline recording and testing at each time point (Sajikumar et al. 2005a).

Ryanodine (RYA, $10 \mu \mathrm{M}$, dissolved in DMSO; Sigma Aldrich) and caffeine (10 mM, 1,3,7-Trimethylxanthine, dissolved in distilled water; Sigma Aldrich) were prepared immediately before bath application. The final concentration of DMSO was $0.1 \%$, a concentration that has no effect on basal synaptic transmission (Navakkode et al. 2004). The CaMKII inhibitors KN-62 (1-[NO-bis1,5-isoquinolinesulfonyl]- $N$-methyl-L-tyrosyl-4-phenylpiperazine; Calbiochem) and AIP (autocamtide-2-related inhibitory peptide; Calbiochem) (Nayak et al. 1996; Blank et al. 2002; Yang et al. 2004; Pedersen et al. 2005) were dissolved in DMSO as a stock solution (5 $\mathrm{mM})$. The required volume of $5 \mu \mathrm{M}$ was dissolved in ACSF 

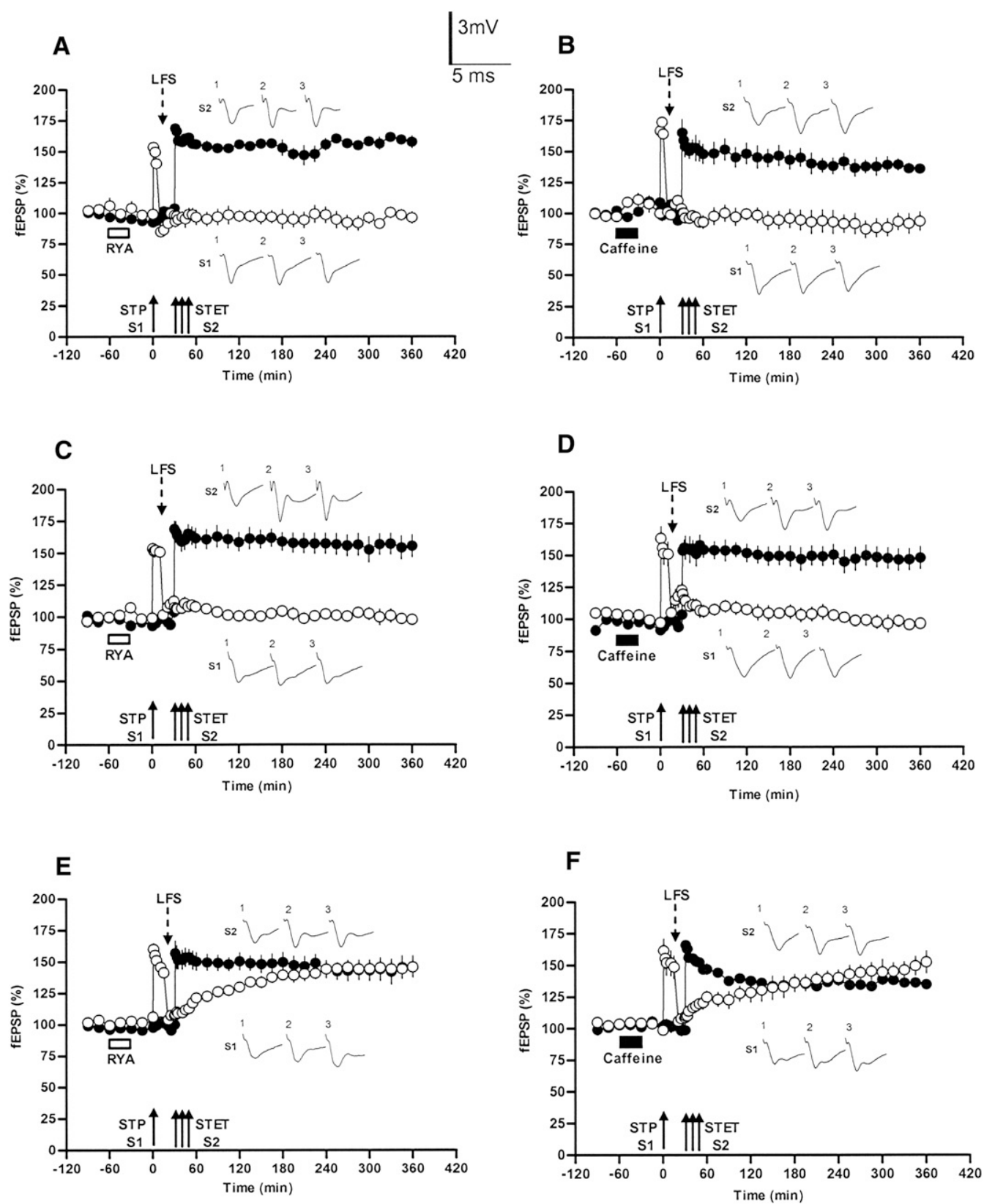

Figure 5. Depotentiated primed STP does not show synaptic tagging/capture. The effect of induction of late-LTP in S2 (•) 30 min after the induction of primed STP in S1 (O) and LFS of S1 either $5 \min (A, B)(n=5, n=4), 10 \min (C, D)(n=5, n=4)$, or $15 \min (D, E)(n=5, n=4)$. Delivery of LFS stimulation 5 or 10 min after the induction of primed STP $(A-D)$ prevented capture or utilization of proteins generated in response to the S2 tetanization. LFS 15 min after primed STP resulted in depotentiation and an incomplete recovery of the potentials, followed by transformation to late-LTP through synaptic tagging/ capture $(D, E)(O ; n=5, n=4)$. Error bars indicate SEM. Symbols and traces as in Figure 4.

immediately before bath application. The used concentration of 5 $\mu \mathrm{M}$ of AIP is specific for CaMKII, although higher concentrations above $10 \mu \mathrm{M}$ may also inhibit PKA and PKC (Ishida et al. 2001). The myristoylated pseudosubstrate peptide myr-ZIP (Biosource) and its control peptide scr-myr-ZIP were prepared in distilled water as a stock solution $(5 \mathrm{mM})$. The required volume of $1 \mu \mathrm{M}$ was dissolved in ACSF immediately before bath application. Suitable precautions were taken to ensure that photosensitive drugs were protected from exposure to light.

The average values of the slope function of the field EPSP $(\mathrm{mV} / \mathrm{ms})$ per time point were analyzed using the Wilcoxon signed rank test when compared within one group, or the Mann-Whitney $U$-test when data were compared between groups; $P<0.05$ was considered as statistically significantly different (Sajikumar et al. 2007a,b).

\section{Acknowledgments}

We are very grateful to Sheeja Navakkode for her critical comments on the manuscript, Lai Quiwen and Zhang Wei for their excellent technical assistance, and Dr. Todd Sacktor for providing scr-ZIP. S.S. was supported by a new investigator grant from the National Medical Research Council (NMRC/NIG/0021/2008) of Singapore and Z.C.X. by NMRC and DCR grants. W.C.A. was supported by the Health Research Council of New Zealand and a James Cook Fellowship from the New Zealand Royal Society. 


\section{References}

Abraham, W.C. 1999. Metaplasticity: Key element in memory and learning? News Physiol. Sci. 14: 85. doi: 1548-9213/99.

Abraham, W.C. 2008. Metaplasticity: Tuning synapses and networks for plasticity. Nat. Rev. Neurosci. 9: 387. doi: 10.1038/nrn2356.

Alarcon, J.M., Barco, A., and Kandel, E.R. 2006. Capture of the late phase of long-term potentiation within and across the apical and basilar dendritic compartments of CA1 pyramidal neurons: Synaptic tagging is compartment restricted. J. Neurosci. 26: 256-264.

Balschun, D., Wolfer, D.P., Bertocchini, F., Barone, V., Conti, A., Zuschratter, W., Missiaen, L., Lipp, H.P., Frey, J.U., and Sorrentino, V. 1999. Deletion of the ryanodine receptor type 3 (RyR3) impairs forms of synaptic plasticity and spatial learning. EMBO J. 18: 5264-5273.

Barco, A., Lopez, D.A., and Alarcon, J.M. 2008. Synapse-specific stabilization of plasticity processes: The synaptic tagging and capture hypothesis revisited 10 years later. Neurosci. Biobehav. Rev. 32: 831-851.

Blank, T., Nijholt, I., Eckart, K., and Spiess, J. 2002. Priming of long-term potentiation in mouse hippocampus by corticotropin-releasing factor and acute stress: Implications for hippocampus-dependent learning. $J$. Neurosci. 22: 3788-3794.

Bortolotto, Z.A. and Collingridge, G.L. 1999. Evidence that a novel metabotropic glutamate receptor mediates the induction of long-term potentiation at CA1 synapses in the hippocampus. Biochem. Soc. Trans 27: $170-174$.

Bortolotto, Z.A., Bashir, Z.I., Davies, C.H., and Collingridge, G.L. 1994. A molecular switch activated by metabotropic glutamate receptors regulates induction of long-term potentiation. Nature 368: 740-743.

Coan, E.J., Irving, A.J., and Collingridge, G.L. 1989. Low-frequency activation of the NMDA receptor system can prevent the induction of LTP. Neurosci. Lett. 105: 205-210.

Cohen, A.S. and Abraham, W.C. 1996. Facilitation of long-term potentiation by prior activation of metabotropic glutamate receptors. $J$. Neurophysiol. 76: 953-962.

Cohen, A.S., Raymond, C.R., and Abraham, W.C. 1998. Priming of longterm potentiation induced by activation of metabotropic glutamate receptors coupled to phospholipase C. Hippocampus 8: 160-170.

Frey, U. and Morris, R.G. 1997. Synaptic tagging and long-term potentiation. Nature 385: 533-536.

Frey, U. and Morris, R.G. 1998a. Synaptic tagging: Implications for late maintenance of hippocampal long-term potentiation. Trends Neurosci. 21: $181-188$.

Frey, U. and Morris, R.G. 1998b. Weak before strong: Dissociating synaptic tagging and plasticity-factor accounts of late-LTP. Neuropharmacology 37: 545-552.

Govindarajan, A., Kelleher, R.J., and Tonegawa, S. 2006. A clustered plasticity model of long-term memory engrams. Nat. Rev. Neurosci. 7: 575-583.

Hernandez, A.I., Blace, N., Crary, J.F., Serrano, P.A., Leitges, M., Libien, J.M., Weinstein, G., Tcherapanov, A., and Sacktor, T.C. 2003. Protein kinase $\mathrm{M} \zeta$ synthesis from a brain mRNA encoding an independent protein kinase $C \zeta$ catalytic domain. Implications for the molecular mechanism of memory. J. Biol. Chem. 278: 40305-40316.

Ireland, D.R. and Abraham, W.C. 2002. Group I mGluRs increase excitability of hippocampal CA1 pyramidal neurons by a PLCindependent mechanism. J. Neurophysiol. 88: 107-116.

Ishida, A., Shigeri, Y., Tatsu, Y., Endo, Y., Kameshita, I., Okuno, S., Kitani, T., Takeuchi, M., Yumoto, N., and Fujisawa, H. 2001. Substrate specificity of $\mathrm{Ca}^{2+} /$ calmodulin-dependent protein kinase phosphatase: Kinetic studies using synthetic phosphopeptides as model substrates. J. Biochem. 129: 745-753.

Kelleher III., R.J., Govindarajan, A., and Tonegawa, S. 2004. Translational regulatory mechanisms in persistent forms of synaptic plasticity. Neuron 44: $59-73$.

Ling, D.S., Benardo, L.S., and Sacktor, T.C. 2006. Protein kinase M $\zeta$ enhances excitatory synaptic transmission by increasing the number of active postsynaptic AMPA receptors. Hippocampus 16: 443-452.

Manahan-Vaughan, D. and Reymann, K.G. 1997. Group 1 metabotropic glutamate receptors contribute to slow-onset potentiation in the rat CA1 region in vivo. Neuropharmacology 36: 1533-1538.

Martin, S.J. 1998. Time-dependent reversal of dentate LTP by $5 \mathrm{~Hz}$ stimulation. Neuroreport 9: 3775-3781.

Martin, K.C. and Kosik, K.S. 2002. Synaptic tagging-who's it? Nat. Rev. Neurosci. 3: 813-820.

McPherson, P.S., Kim, Y.K., Valdivia, H., Knudson, C.M., Takekura, H., Franzini-Armstrong, C., Coronado, R., and Campbell, K.P. 1991. The brain ryanodine receptor: A caffeine-sensitive calcium release channel. Neuron 7: 17-25.

Meissner, G. 1986. Ryanodine activation and inhibition of the $\mathrm{Ca}^{2+}$ release channel of sarcoplasmic reticulum. J. Biol. Chem. 261: 6300-6306.

Mel, B.W. 1993. Synaptic integration in an excitable dendritic tree. J. Neurophysiol. 70: 1086-1101.
Mellentin, C., Jahnsen, H., and Abraham, W.C. 2007. Priming of long-term potentiation mediated by ryanodine receptor activation in rat hippocampal slices. Neuropharmacology 52: 118-125.

Navakkode, S., Sajikumar, S., and Frey, J.U. 2004. The type IV-specific phosphodiesterase inhibitor rolipram and its effect on hippocampal long-term potentiation and synaptic tagging. J. Neurosci. 24: 77407744 .

Nayak, A.S., Moore, C.I., and Browning, M.D. 1996. $\mathrm{Ca}^{2+} / \mathrm{calmodulin}$ dependent protein kinase II phosphorylation of the presynaptic protein synapsin I is persistently increased during long-term potentiation. Proc. Natl. Acad. Sci. 93: 15451-15456.

Okamoto, K., Narayanan, R., Lee, S.H., Murata, K., and Hayashi, Y. 2007. The role of CaMKII as an F-actin-bundling protein crucial for maintenance of dendritic spine structure. Proc. Natl. Acad. Sci. 104: 6418-6423.

Pedersen, L.M., Lien, G.F., Bollerud, I., and Gjerstad, J. 2005. Induction of long-term potentiation in single nociceptive dorsal horn neurons is blocked by the CaMKII inhibitor AIP. Brain Res. 1041: 66-71.

Raymond, C.R. 2007. LTP forms 1, 2 and 3: Different mechanisms for the "long" in long-term potentiation. Trends Neurosci. 30: 167-175.

Raymond, C.R., Thompson, V.L., Tate, W.P., and Abraham, W.C. 2000. Metabotropic glutamate receptors trigger homosynaptic protein synthesis to prolong long-term potentiation. J. Neurosci. 20: 969-976.

Rousseau, E., Smith, J.S., and Meissner, G. 1987. Ryanodine modifies conductance and gating behavior of single $\mathrm{Ca}^{2+}$ release channel. Am. J. Physiol. 253: C364-C368.

Sacktor, T.C. 2008. PKM $\zeta$, LTP maintenance, and the dynamic molecular biology of memory storage. Prog. Brain Res. 169: 27-40.

Sajikumar, S. and Frey, J.U. 2004a. Late-associativity, synaptic tagging, and the role of dopamine during LTP and LTD. Neurobiol. Learn. Mem. 82: $12-25$.

Sajikumar, S. and Frey, J.U. 2004b. Resetting of "synaptic tags" is time- and activity-dependent in rat hippocampal CA1 in vitro. Neuroscience 129: 503-507.

Sajikumar, S., Navakkode, S., and Frey, J.U. 2005a. Protein synthesisdependent long-term functional plasticity: Methods and techniques. Curr. Opin. Neurobiol. 15: 607-613.

Sajikumar, S., Navakkode, S., Sacktor, T.C., and Frey, J.U. 2005b. Synaptic tagging and cross-tagging: The role of protein kinase $\mathrm{M} \zeta$ in maintaining long-term potentiation but not long-term depression. J. Neurosci. 25: 5750-5756.

Sajikumar, S., Navakkode, S., and Frey, J.U. 2007a. Identification of compartment- and process-specific molecules required for "synaptic tagging" during long-term potentiation and long-term depression in hippocampal CA1. J. Neurosci. 27: 5068-5080.

Sajikumar, S., Navakkode, S., Korz, V., and Frey, J.U. 2007b. Cognitive and emotional information processing: Protein synthesis and gene expression. J. Physiol. 584: 389-400.

Serrano, P., Yao, Y., and Sacktor, T.C. 2005. Persistent phosphorylation by protein kinase $\mathrm{M} \zeta$ maintains late-phase long-term potentiation. J. Neurosci. 25: 1979-1984.

Sossin, W.S. 1996. Mechanisms for the generation of synapse specificity in long-term memory: The implications of a requirement for transcription. Trends Neurosci. 19: 215-218.

van Staveren, W.C., Markerink-van Ittersum, M., Steinbusch, H.W., and de Vente, J. 2001. The effects of phosphodiesterase inhibition on cyclic GMP and cyclic AMP accumulation in the hippocampus of the rat. Brain Res. 888: 275-286.

Yang, H.W., Hu, X.D., Zhang, H.M., Xin, W.J., Li, M.T., Zhang, T., Zhou, L.J., and Liu, X.G. 2004. Roles of CaMKII, PKA, and PKC in the induction and maintenance of LTP of C-fiber-evoked field potentials in rat spinal dorsal horn. J. Neurophysiol. 91: 1122-1133.

Yao, Y., Kelly, M.T., Sajikumar, S., Serrano, P., Tian, D., Bergold, P.J., Frey, J.U., and Sacktor, T.C. 2008. PKM $\zeta$ maintains late long-term potentiation by $\mathrm{N}$-ethylmaleimide-sensitive factor/GluR2-dependent trafficking of postsynaptic AMPA receptors. J. Neurosci. 28: 78207827.

Yoshimura, H. 2005. The potential of caffeine for functional modification from cortical synapses to neuron networks in the brain. Curr. Neuropharmacol. 3: 309-316.

Young, J.Z. and Nguyen, P.V. 2005. Homosynaptic and heterosynaptic inhibition of synaptic tagging and capture of long-term potentiation by previous synaptic activity. J. Neurosci. 25: 7221-7231.

Young, J.Z., Isiegas, C., Abel, T., and Nguyen, P.V. 2006. Metaplasticity of the late-phase of long-term potentiation: A critical role for protein kinase A in synaptic tagging. Eur. J. Neurosci. 23: 1784-1794.

Youssef, F.F., Addae, J.I., and Stone, T.W. 2006. NMDA-induced preconditioning attenuates synaptic plasticity in the rat hippocampus. Brain Res. 1073-1074: 183-189.

Received October 10, 2008; accepted in revised form December 18, 2008. 


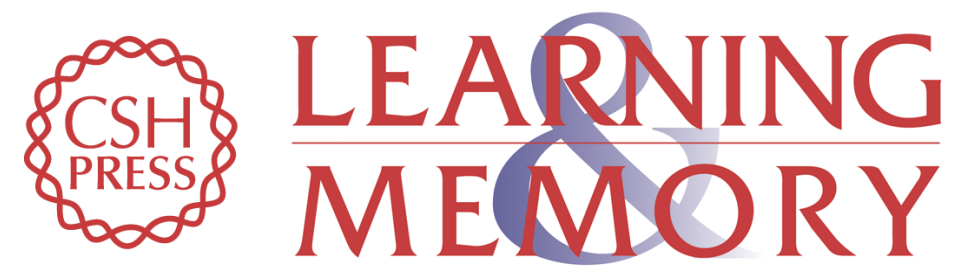

\section{Priming of short-term potentiation and synaptic tagging/capture mechanisms by ryanodine receptor activation in rat hippocampal CA1}

Sreedharan Sajikumar, Qin Li, Wickliffe C. Abraham, et al.

Learn. Mem. 2009, 16:

Access the most recent version at doi:10.1101/lm.1255909

References This article cites 50 articles, 14 of which can be accessed free at: http://learnmem.cshlp.org/content/16/3/178.full.html\#ref-list-1

License

Email Alerting

Receive free email alerts when new articles cite this article - sign up in the box at the Service top right corner of the article or click here. 